\title{
FAKTOR YANG BERHUBUNGAN DENGAN RUAM POPOK PADA BAYI BARU LAHIR
}

\author{
Anik Rustiyaningsih ${ }^{1, *}$, Yeni Rustina ${ }^{2}$, Tuti Nuraini ${ }^{2}$ \\ ${ }^{1}$ Staf Akademik Departemen Keperawatan Anak dan Maternitas Fakultas Kedokteran, Kesehatan \\ Masyarakat, dan Keperawatan, Universitas Gadjah Mada Yogyakarta \\ J1. Farmako, Sekip Utara, Yogyakarta, 55281, Indonesia \\ ${ }^{2}$ Staf Akademik Keperawatan Anak Fakultas Ilmu Keperawatan Universitas Indonesia, \\ Kampus FIK UI, J1. Prof. Dr. Bahder Djohan, Depok, Jawa Barat -16424, Indonesia \\ *)E-mail: anik.rustiyaningsih@ugm.ac.id
}

Diterima: Mei 2018, diterbitkan: Agustus 2018

\begin{abstract}
ABSTRAK
Tujuan Penelitian: Tujuan penelitian ini adalah untuk mengetahui faktor-faktor yang berhubungan dengan kejadian ruam popok pada bayi baru lahir di ruang perinatal sebuah rumah sakit rujukan di Jakarta, Indonesia. Metode: Penelitian ini menggunakan desain cross-sectional dengan metode survey. Sampel $(\mathrm{n}=95)$ dipilih menggunakan teknik consecutive sampling. Kejadian ruam popok diobservasi menggunakan instrumen DDSIS (Diaper Dermatitis Severity Index Score). Instrumen dijamin validitas isinya dengan konsultasi ahli. Uji validitas konstruk dengan statistik korelasi Pearson Product Moment. Nilai korelasi antar item tiap sub skala DDSIS yaitu eritema/kemerahan ( $\mathrm{r}=0,767)$, papula/pustula (r=0,733) dan erosi $(\mathrm{r}=0,711)$ lebih besar dari $\mathrm{r}$ tabel (r=0,2017). Uji reliabilitas didapatkan nilai Cronbach's Alpha sebesar 0,77. Nilai Kappa untuk uji inter-rater reliability oleh dua orang observer yaitu 0,95. Analisis multivariat yang digunakan adalah regresi logistik ganda. Hasil: Ada dua faktor yang berhubungan dengan kejadian ruam popok yaitu infeksi mikroorganisme $(p$-value $=0,015 ; \mathrm{OR}=7,6)$ dan lama hari rawat $(p$-value $=0,012 ; \mathrm{OR}=3,9)$. Faktor yang paling dominan adalah infeksi mikroorganisme. Diskusi: Bayi baru lahir dengan diagnosis penyakit infeksi dan dirawat delapan hari atau lebih memiliki risiko yang lebih tinggi terhadap kejadian ruam popok. Kesimpulan: Hasil penelitian ini mengindikasikan perlunya evaluasi kembali pelaksanaan Universal Standard Precaution di rumah sakit.
\end{abstract}

Kata kunci: ruam popok, DDSIS (Diaper Dermatitis Severity Index Score), bayi baru lahir, rumah sakit, faktor risiko

\section{FACTORS ASSOCIATED WITH NEWBORNS' DIAPER RASH}

\section{ABSTRACT}

Objective: The purpose of this study was to determine factors associated with newborns' diaper rash in a referral hospital in Jakarta, Indonesia. Method: This study used a cross-sectional design survey. The samples ( $n=95)$ were selected using consecutive sampling technique. The prevalence of diaper rash was observed using a DDSIS (Diaper Dermatitis Severity Index Score). The content validity of the instrument was tested using expert judgment. The construct validity values of DDSIS subscales were: erythema/redness $(r=0.767)$, papules/pustules $(r=0.733)$ and erosion $(r=0.711)$. All the values were greater than $r$ table $(r=0.2017)$. The reliability was showed by Cronbach's Alpha value $(\alpha=0.77)$. Kappa value for inter-rater reliability test by two observers was 0.95 . The multivariate analysis was conducted using multiple logistic regression. Results: There are two factors related to newborns' diaper rash. These factors are microorganism infection $(p$-value $=0.015 ; O R=7.6)$ and length of stay ( $p$-value=0.012; OR=3.9). The most dominant factor is microorganism infection. Discussion: Newborns diagnosed with an infectious disease and hospitalized eight days or more have a higher risk for diaper rash. Conclusion: The results of this study indicate the need to re-evaluate the implementation of Universal Standard Precaution in hospital.

Keywords: diaper rash, DDSIS (Diaper Dermatitis Severity Index Score), newborns, hospitals, risk factors. 


\section{LATAR BELAKANG}

Bayi baru lahir adalah bayi usia 0-28 hari. Lapisan penghalang (barrier) pada kulit bayi belum terbentuk sempurna sampai usia satu tahun, yang berarti menyebabkan perlunya perlindungan dalam hal distribusi dan pengangkutan air melalui permukaan kulit. Apabila terkena gesekan, urin, atau feses akan menyebabkan kulit bayi lebih mudah lecet dan secara umum berkontribusi terhadap kejadian ruam popok (Jackson, 2008).

Ruam popok (diaper rash, napkin dermatitis, nappy rash) atau diaper dermatitis secara umum digunakan untuk mendiskripsikan beberapa kerusakan dan peradangan kulit pada daerah sekitar popok (diaper). Laporan mengenai insidensi dan umur terjadinya serangan sangat bervariasi, berhubungan dengan perbedaan penggunaan diaper, toilet training, kebersihan, dan usia anak. Prevalensi ruam popok pada bayi berkisar antara $7-35 \%$ dan dapat terjadi pada awal usia satu minggu (Horii \& Prossick, 2012). Insiden meningkat tiga kali lipat pada kejadian diare (Mersch \& Shiel, 2012). Di Indonesia laporan mengenai angka kejadian ruam popok khususnya pada bayi baru lahir yang akurat belum tersedia.

Terdapat banyak faktor yang berisiko terhadap kejadian ruam popok. Visscher (2009) menyebutkan faktor-faktor tersebut diantaranya adalah meningkatnya hidrasi kulit, kontak dengan iritan kulit (urin, feses, enzim dalam feses, garam empedu), gesekan mekanik (kulit dengan kulit, popok dengan kulit), $\mathrm{pH}$ kulit, status gizi dan diet (komposisi fekal), usia kehamilan, penggunaan terapi antibiotik, adanya diare dan kondisi medis.

Ruam popok sering membuat bayi tidak nyaman. Rasa gatal, perih, risih dan kadang terasa sakit menyebabkan bayi gelisah dan rewel. Pengetahuan tentang faktor-faktor risiko ruam popok diperlukan untuk dapat meminimalkan atau menangani masalah ruam popok.

\section{METODE}

Metode penelitian yang digunakan adalah metode survey dengan desain crosssectional. Penelitian ini mengikutsertakan 95 responden bayi baru lahir yang menggunakan popok dan dirawat lebih dari tiga hari di ruang perinatologi sebuah rumah sakit rujukan di Jakarta, Indonesia. Data didapatkan dari rekam medis dan observasi. Data yang diperoleh dari rekam medis berupa data demografi dan faktor-faktor risiko ruam popok (usia gestasi, diet bayi, frekuensi Buang Air Besar (BAB), jenis popok, frekuensi mandi, frekuensi penggantian popok, waktu bebas popok, penggunaan antibiotik, penggunaan krim popok, penggunaan alat pembersih popok, riwayat alergi, lama hari rawat, dan infeksi kuman/mikroorganisme). Data yang diperoleh dari observasi adalah data ruam popok. Observasi dilakukan oleh dua orang observer termasuk peneliti yang sudah dilakukan penyamaan persepsi dan interrater reliability.

Instrumen DDSIS (Diaper Dermatitis Severity Index Score) digunakan untuk menilai derajat keparahan ruam popok (skor 0-8). Derajat ruam ini dibedakan menjadi tidak ada ruam (skor 0), ruam ringan (skor 1-2), ruam sedang (skor 3-4) dan ruam berat (skor 5-8) (Mantoya, 2008). Uji validitas instrumen penelitian dilakukan melalui expert judgment untuk validitas isi, dan Pearson Product Moment untuk validitas konstruk yang menunjukkan nilai koefisien korelasi eritema/kemerahan $(r=0,767)$, papula/pustula $(r=0,733)$ dan erosi $(r=0,711)$. Ketiga nilai $r$ tersebut berada di atas nilai $r$ tabel $(r=0,2017)$ untuk n=95 (uji terpakai). Uji reliabilitas DDSIS menunjukkan nilai Cronbach's Alpha sebesar 0,77 . Diperkuat dengan nilai Kappa untuk uji inter-rater reliability yang dilakukan oleh dua 
orang rater yaitu 0,95 . Hasil ini menunjukkan DDSIS valid dan reliabel untuk mengukur ruam popok dan derajatnya. Penelitian ini mendapatkan Ethical Clearance dari Komite Etik Penelitian Fakultas IImu Keperawatan Universitas Indonesia No. 73/H2.F12.D/ HKP.02.04/2013.

\section{HASIL PENELITIAN}

Hasil penelitian ini dijelaskan pada tabel 1 sampai dengan tabel 5 . Tabel 1 menunjukkan sebaran karakteristik responden. Sebagian besar responden berjenis kelamin lakilaki, BBLR (Berat Badan Lahir Rendah), terdiagnosis NKB-SMK (Neonatus Kurang Bulan-Sesuai Masa Kehamilan) dan penyakit infeksius.

Tabel 2 menunjukkan angka kejadian ruam popok yaitu sebesar $26,3 \%$, terdiri dari ruam popok ringan $(10,5 \%)$ yang paling banyak, disusul oleh ruam popok berat $(9,5 \%)$ dan ruam popok sedang $(6,3 \%)$. Tabel 3 menunjukkan sebaran kriteria dalam instrumen DDSIS (eritema, papula/pustula, dan erosi). Responden dengan ruam popok paling banyak memiliki eritema ringan (10,5\%), papula/pustula sedikit $(7,4 \%)$, dan tidak ada erosi $(91,6 \%)$.

Tabel 4 menunjukkan hasil analisis regresi logistik sederhana untuk menyeleksi kandidat variabel yang akan dimasukkan dalam uji regresi logistik ganda ( $p$ value $<0,25)$. Variabel yang terseleksi adalah frekuensi $B A B$, frekuensi mandi, waktu bebas popok, lama hari rawat, dan infeksi kuman/ mikroorganisme.

Tabel 5 menunjukkan hasil analisis multivariat regresi logistik ganda. Hasil ini menunjukkan bahwa variabel yang berhubungan bermakna dengan kejadian ruam popok adalah lama hari rawat dan infeksi kuman/mikroorganisme. Odds Ratio (OR) dari variabel infeksi kuman/ mikroorganisme adalah 7,6 artinya bayi baru lahir yang terinfeksi kuman/mikroorganisme akan berpeluang terjadi ruam popok sebesar 8 kali lebih tinggi dibandingkan dengan bayi baru lahir yang tidak terinfeksi kuman/ mikroorganisme setelah dikontrol faktor lama hari rawat, frekuensi mandi dan waktu bebas popok. OR dari variabel lama hari rawat adalah 3,9 artinya bayi baru lahir yang dirawat lebih dari atau sama dengan 8 hari akan berpeluang terjadi ruam popok sebesar 4 kali lebih tinggi dibandingkan dengan bayi baru lahir yang dirawat kurang dari 8 hari setelah dikontrol faktor infeksi kuman/mikroorganisme, frekuensi mandi dan waktu bebas popok. Variabel frekuensi $B A B$ dikeluarkan dari persamaan regresi karena variabel ini setelah dikeluarkan tidak merubah nilai OR lebih dari $10 \%$.

\section{DISKUSI}

Prevalensi ruam popok pada bayi baru lahir dalam penelitian ini tidak jauh perbedaannya dibandingkan dengan penelitian-penelitian sebelumnya yang dilakukan di beberapa negara. Di China penelitian yang dilakukan oleh Li, Zhu, \& Dai (2012) menunjukkan prevalensi ruam popok sebesar $43,8 \%$. Penelitian yang dilakukan oleh Adalat, Wall, \& Goodyear (2007) di Inggris menunjukkan $16 \%$ kejadian ruam popok. Beberapa studi pustaka juga menyebutkan angka kejadian ruam popok bervariasi antara 7-35\% (Mersch \& Shiel, 2011).

Infeksi kuman / mikroorganisme menunjukkan hubungan yang paling penting terhadap kejadian ruam popok pada bayi baru lahir dibandingkan dengan variabel independen lainnya karena memiliki OR yang paling besar. Humphrey, Bergman, \& Au (2006) dalam penelitiannya menunjukkan bahwa mikroorganisme utama yang berhubungan dengan kasus ruam popok yang parah adalah Candida albicans. Penelitian ini memberikan informasi bahwa 
terdapat korelasi positif antara keparahan klinis diaper dermatitis dengan adanya tingkat Candida albicans pada popok, mulut, dan anus bayi. Adanya pustula satelit merupakan karakteristik ruam popok Candida, dan memungkinkan ruam popok karena jamur ini bisa dibedakan dengan jenis ruam popok lain. Pemeriksaan $\mathrm{KOH}$ (Potassium Hydroxide) dan kultur sensitifitas adalah pemeriksaan laboratorium yang dapat dilakukan untuk memastikan diagnosa ruam popok Candida (Mersch \& Stoppler, 2009).

Sumber utama infeksi Candida adalah flora normal dalam tubuh pada pasien dengan sistem imun menurun. Dapat juga berasal dari luar tubuh, contohnya pada bayi baru lahir mendapat Candida dari vagina ibunya (pada waktu lahir atau masa hamil) atau dari staf rumah sakit, dimana angka terbawanya sampai 58\%. Transmisi Candida antara staf rumah sakit dengan pasien, pasien dengan pasien biasanya muncul pada unit khusus misalnya unit neonatus. Hal ini dapat terjadi karena adanya salah satu faktor predisposisi endogen yaitu umur (bayi lebih mudah terkena infeksi nosokomial karena status imunnya belum sempurna) (Simatupang, 2009).

Penelitian Kartono (2009) menunjukkan bahwa lama hari rawat berhubungan dengan kejadian infeksi nosokomial. Candida yang menjadi salah satu infeksi nosokomial yang paling penting di seluruh dunia (Simatupang, 2009), juga merupakan infeksi yang sering dikaitkan dengan kasus ruam popok (Humphrey, Bergman, \& Au, 2006). Semakin lama hari rawat maka akan semakin terpapar terhadap agen patogen dari rumah sakit sehingga infeksi nosokomial pun akan semakin tinggi (Kartono, 2009).

Waktu bebas popok berdasarkan hasil observasi menunjukkan bahwa bayi baru lahir selama 24 jam menggunakan diapers, sehingga waktu bebas popok hanya didapat ketika bayi-bayi ini diganti popok dan dimandikan. Hasil ini sesuai dengan pernyataan yang dipaparkan oleh Humphrey, Bergman, \& Au (2006) bahwa penggunaan popok yang terus-menerus menjadi akar permasalahan ruam popok. Memaksimalkan waktu bebas popok merupakan strategi pencegahan yang banyak direkomendasikan, tetapi sangat tidak praktis. Seringnya penggantian popok dinilai penting untuk menjaga kekeringan dan menjaga terpisahnya urin dan feses.

Penelitian ini menunjukkan tidak ada hubungan yang bermakna antara frekuensi mandi dengan kejadian ruam popok pada bayi baru lahir. Berbeda dengan hasil penelitian yang dilakukan oleh $\mathrm{Li}$, Zhu, \& Dai (2012) yang menunjukkan hubungan yang bermakna pada anak usia 1-24 bulan yang dimandikan kurang dari $3 \mathrm{kali} / \mathrm{minggu}$, dibandingkan dengan yang dimandikan lebih dari atau sama dengan $3 \mathrm{kali} / \mathrm{minggu}$.

Frekuensi BAB menunjukkan hasil yang tidak bermakna dengan kejadian ruam popok pada bayi baru lahir dan tidak ditemukan kasus diare. Penelitian yang dilakukan oleh Li, Zhu, \& Dai (2012) menunjukkan bahwa ada tidaknya diare secara signifikan berhubungan dengan kejadian ruam popok pada anak usia 1-24 bulan. Penelitian yang dilakukan oleh Adalat, Wall, \& Goodyear (2007) juga menunjukkan bahwa terdapat hubungan yang bermakna antara kasus diare dengan kejadian ruam popok pada anak yang dirawat di rumah sakit.

Usia gestasi menunjukkan tidak ada hubungan yang bermakna dengan kejadian ruam popok. Menurut teori yang dipaparkan oleh Jackson (2008) bahwa usia gestasi pada saat bayi dilahirkan mempengaruhi kematangan lapisan kulit. Hal ini berhubungan dengan perkembangan kulit dan integritas stratum korneum sebagai barrier pelindung kulit. Stratum korneum inilah yang memiliki peranan penting dalam kejadian ruam 
popok karena salah satunya berfungsi mencegah keracunan dari absorbsi obatobatan dan bahan kimia dari tinja dan urin, dan melindungi tubuh dari mikroorganisme. Penelitian ini sesuai dengan teori Jackson (2008) tersebut, dimana lebih banyak jumlah bayi prematur yang menderita ruam popok (14 bayi) dibandingkan dengan bayi cukup bulan yang menderita ruam popok (11 bayi). Namun demikian, perbedaan hasil ini tidak bermakna secara signifikan.

Hasil penelitian ini menunjukkan bahwa diet bayi tidak berhubungan bermakna dengan kejadian ruam popok pada bayi baru lahir. Penelitian ini sesuai dengan hasil penelitian sebelumnya yang dilakukan oleh Adalat, Wall, \& Goodyear (2007) dimana tidak ada hubungan yang bermakna antara diet bayi dengan kejadian ruam popok.

Hubungan antara jenis popok dengan kejadian ruam popok pada bayi baru lahir tidak bisa diketahui karena tidak adanya variasi data. Penelitian yang dilakukan Adalat, Wall, \& Goodyear (2007) menjelaskan tidak adanya hubungan antara tipe dan merk diapers terhadap kejadian ruam popok pada anak yang dirawat di rumah sakit. Penelitian Li, Zhu, \& Dai (2012) menunjukkan hasil yang berbeda yaitu adanya hubungan yang signifikan antara penggunaan jenis popok kain, diaper, campuran popok kain dan diaper terhadap kejadian ruam popok.

Frekuensi penggantian popok dilakukan rata-rata 4 kali setiap hari, atau setiap 6 jam sekali menunjukkan tidak ada hubungan yang bermakna dengan kejadian ruam popok pada bayi baru lahir. Penelitian yang dilakukan oleh Li, Zhu, \& Dai (2012) menunjukkan bahwa penggantian popok lebih dari atau sama dengan 6 kali/hari terbukti secara signifikan menurunkan kejadian ruam popok dari pada yang diganti kurang dari frekuensi tersebut. Pernyataan yang sama disampaikan oleh Humphrey, Bergman, \& Au (2006) bahwa popok harus diganti setiap basah atau kotor, atau setidaknya 3-4 jam dan lebih sering pada neonatus. Penelitian yang dilakukan oleh Adalat, Wall, \& Goodyear (2007) juga menunjukkan hasil yang sama bahwa terdapat hubungan yang bermakna antara kejadian ruam popok dengan frekuensi penggantian popok antara kelompok yang diganti setiap 3-4 jam sekali dengan kelompok yang diganti kurang dari itu.

Penggunaan antibiotik menunjukkan hasil yang tidak bermakna dengan kejadian ruam popok. Teori yang menjelaskan bahwa ruam pada popok dapat dipicu oleh penggunaan antibiotik (Visscher, 2009) dalam penelitian ini tidak terbukti.

Teori dari Humphrey, Bergman, \& Au (2006) menyatakan bahwa krim popok bisa berfungsi sebagai penghalang (barrier). Penghalang ini dapat meminimalkan kehilangan air transepidermal dan menurunkan permeabilitas terhadap iritan dengan membentuk lapisan lipid di atas permukaan kulit. Penghalang ini juga meminimalkan gesekan pada kulit. Penelitian ini tidak bisa membuktikan teori di atas, karena di tempat penelitian penggunaan krim popok merupakan anti Candida (jamur) tidak diberikan sebelum terjadi ruam popok, melainkan sebagai pengobatan setelah terjadi ruam.

Hasil penelitian ini memberikan data tidak adanya variasi pada penggunaan alat pembersih popok dan riwayat alergi pada responden. Hal tersebut menyebabkan tidak dapat diketahui hubungannya dengan kejadian ruam popok pada bayi baru lahir. Tisu basah diyakini berkontribusi terhadap kejadian ruam popok (Humphrey, Bergman, \& Au, 2006). Pembersihan sederhana dengan air dan kain yang lembut cenderung mengurangi iritasi kulit dari pada menggunakan tisu sekali pakai (Mersch \& Shiel, 2012). Kedua pernyataan tersebut sesuai dengan hasil penelitian 
ini bahwa semua bayi baru lahir sudah menggunakan aquabides + kapas/kasa untuk membersihkan area pemakaian popok, dan bukan tisu basah (tisu sekali pakai). Mersch \& Shiel (2012) menjelaskan bahwa reaksi alergi adalah salah satu penyebab dari ruam popok. Pernyataan tersebut belum bisa dibuktikan dalam penelitian ini.

\section{SIMPULAN}

Simpulan yang dapat diambil dari penelitian ini adalah masih tingginya angka kejadian ruam popok pada bayi baru lahir yang dirawat di rumah sakit $(26,3 \%)$ dan sebagian besar responden terdiagnosis penyakit infeksi $(76,8 \%)$. Selain itu juga diketahui adanya hubungan yang bermakna (signifikan) antara infeksi kuman/mikroorganisme dan lama hari rawat terhadap kejadian ruam popok pada bayi baru lahir. Faktor yang paling dominan adalah infeksi kuman/mikroorganisme. Hasil penelitian mengindikasikan pentingnya evaluasi kembali pelaksanaan Universal Standard Precaution terutama cuci tangan yang telah ditetapkan di ruang rawat perinatal.

Faktor-faktor yang lain seperti usia gestasi, diet bayi, frekuensi BAB, frekuensi mandi, frekuensi ganti popok, waktu bebas popok, penggunaan antibiotik, penggunaan krim popok diketahui tidak hubungan dengan kejadian ruam popok pada bayi baru lahir. Adanya perbedaan dengan studi pustaka lain memberikan peluang untuk dilakukannya penelitian yang sama dengan jumlah responden yang lebih besar.

Tidak diketahui hubungan antara jenis popok, penggunaan alat pembersih popok, dan riwayat alergi terhadap kejadian ruam popok, karena tidak adanya variasi data penelitian. Hal tersebut menjadi penting dilakukan penelitian yang sama pada responden yang menunjukkan variasi pada varibel-variabel tersebut.

Diagnosis Medis, Mei, $2013(n=95)$

\begin{tabular}{lcc}
\hline \multicolumn{1}{c}{ Variabel } & Jumlah & Persentase (\%) \\
\hline Jenis Kelamin & & \\
$\quad$ Laki-laki & 61 & 64,2 \\
Perempuan & 34 & 35,8 \\
\hline Total & 95 & 100 \\
\hline Berat Badan Lahir & & \\
$\quad$ BBLR (<2.500 gr) & 71 & 74,7 \\
$\quad$ Normal $(\geq 2.500$ gr) & 24 & 25,3 \\
\hline Total & 95 & 100 \\
\hline Diagnosis medis saat masuk ruang rawat & & \\
(Berdasarkan BB dan Usia Gestasi) & & \\
$\quad$ NKB-KMK & 1 & 1,0 \\
$\quad$ NKB-SMK & 60 & 63,2 \\
$\quad$ NCB-KMK & 3 & 3,2 \\
$\quad$ NCB-SMK & 31 & 32,6 \\
\hline$\quad$ Total & 95 & 100 \\
\hline Diagnosis medis saat masuk ruang rawat & & \\
(Berdasarkan Penyebab) & & \\
$\quad$ Infeksi & 50 & 52,6 \\
$\quad$ Non Infeksi & 45 & 47,4 \\
\hline$\quad$ Total & 95 & 100 \\
\hline Dial
\end{tabular}

Diagnosis medis kerja (Berdasarkan BB dan Usia

Gestasi) 


\begin{tabular}{|c|c|c|}
\hline Variabel & Jumlah & Persentase (\%) \\
\hline NKB-KMK & 1 & 1,0 \\
\hline NKB-SMK & 60 & 63,2 \\
\hline NCB-KMK & 3 & 3,2 \\
\hline NCB-SMK & 31 & 32,6 \\
\hline Total & 95 & 100 \\
\hline \multicolumn{3}{|c|}{ Diagnosis Medis Kerja (Berdasarkan Penyebab) } \\
\hline Infeksi & 73 & 76,8 \\
\hline Non Infeksi & 22 & 23,2 \\
\hline Total & 95 & 100 \\
\hline
\end{tabular}

Ket: BBLR=Berat Badan Lahir Rendah, BB=Berat Badan, NKB-KMK=Neonatus Kurang Bulan-Kecil Masa Kehamilan, NKB-SMK=Neonatus Kurang Bulan-Sesuai Masa Kehamilan, NCB-KMK=Neonatus Cukup Bulan-Kurang Masa Kehamilan, NCB-SMK=Neonatus Cukup Bulan-Sesuai Masa Kehamilan.

Tabel 2. Distribusi Responden Berdasarkan Kejadian Ruam Popok Mei, $2013(n=95)$

\begin{tabular}{lcc}
\hline Variabel & Jumlah & Persentase (\%) \\
\hline Ruam Popok & & \\
Ringan & 10 & 10,5 \\
Sedang & 6 & 6,3 \\
Berat & 9 & 9,5 \\
Tidak Ruam Popok & 70 & 73,7 \\
\hline Total & 95 & 100 \\
\hline
\end{tabular}

Tabel 3. Distribusi Responden Berdasarkan Eritema,

Papula/Pustula dan Erosi pada Instrumen DDSIS Mei, 2013 ( $\mathrm{n}=95$ )

\begin{tabular}{lcc}
\hline \multicolumn{1}{c}{ DDSIS } & Jumlah & Persentase (\%) \\
\hline Eritema/Kemerahan & 70 & 73,7 \\
Tidak ada & 10 & 10,5 \\
Ringan (merah muda) & 6 & 6.3 \\
Sedang (merah) & 9 & 9,5 \\
Berat (merah daging/beefy red) & 95 & 100 \\
\hline Total & & \\
\hline Papula/Pustula & 78 & 82,1 \\
Tidak ada & 7 & 7,4 \\
Sedikit (1-10) & 4 & 4,2 \\
Multipel (11-20) & 5 & 5,3 \\
Banyak (21-40) & 1 & 1,0 \\
Banyak sekali (> 40) & 95 & 100 \\
\hline Total & & \\
\hline Erosi & 87 & 91,6 \\
Tidak ada & 8 & 100 \\
Ada & 95 & \\
\hline Total & & \\
\hline
\end{tabular}


Tabel 4. Hubungan antara Kejadian Ruam Popok dengan Variabel Independen Mei, $2013(n=95)$

\begin{tabular}{|c|c|c|c|c|c|c|c|c|}
\hline \multirow{3}{*}{ Variabel } & \multicolumn{4}{|c|}{ Ruam Popok } & \multirow{2}{*}{\multicolumn{2}{|c|}{ Total }} & \multicolumn{2}{|c|}{ Regresi Logistik Sederhana } \\
\hline & \multicolumn{2}{|c|}{ Tidak } & \multicolumn{2}{|c|}{$\mathrm{Ya}$} & & & \multirow{2}{*}{$p$-value } & \multirow{2}{*}{$\begin{array}{c}\mathrm{OR} \\
95 \% \mathrm{Cl}\end{array}$} \\
\hline & $\mathrm{n}$ & $\%$ & $\mathrm{n}$ & $\%$ & $\mathrm{n}$ & $\%$ & & \\
\hline \multicolumn{9}{|l|}{ Usia Gestasi } \\
\hline Preterm (< 37 minggu) & 46 & 48,4 & 14 & 14,7 & 60 & 63,2 & & 1.506 \\
\hline Aterm (37-42 minggu) & 24 & 25,3 & 11 & 11,6 & 35 & 36,8 & 0,389 & $0.593-3.822$ \\
\hline Postterm (< 42 minggu) & 0 & 0 & 0 & 0 & 0 & 0 & & \\
\hline Total & 70 & 73,3 & 25 & 26,3 & 95 & 100 & & \\
\hline \multicolumn{9}{|l|}{ Diet Bayi } \\
\hline ASI & 4 & 4,2 & 0 & 0 & 4 & 4,2 & & \\
\hline Formula & 36 & 37,9 & 16 & 16,8 & 52 & 54,7 & & \\
\hline ASI dan Formula & 12 & 12,6 & 7 & 7,4 & 19 & 20,0 & & 0.770 \\
\hline Puasa & 18 & 18,9 & 2 & 2,1 & 20 & 21,1 & 0,352 & $0.444-1.335$ \\
\hline Total & 70 & 73,7 & 25 & 26,3 & 95 & 100 & & \\
\hline \multicolumn{9}{|l|}{ Frekuensi BAB } \\
\hline$<2 x$ /hari & 26 & 27,4 & 6 & 6,3 & 32 & 33,7 & & 1.871 \\
\hline$\geq 2 x /$ hari & 44 & 46,3 & 19 & 20,0 & 63 & 66,3 & 0,237 & $0.663-5.284$ \\
\hline Total & 70 & 73,7 & 25 & 26,3 & 95 & 100 & & \\
\hline \multicolumn{9}{|l|}{ Jenis Popok } \\
\hline Popok Kain & 0 & 0 & 0 & 0 & 0 & 0 & & \\
\hline Diapers & 70 & 73,7 & 25 & 26,3 & 95 & 100 & - & - \\
\hline Popok Kain dan Diapers & 0 & 0 & 0 & 0 & 0 & 0 & & \\
\hline Total & 70 & 73,7 & 25 & 26,3 & 95 & 100 & & \\
\hline \multicolumn{9}{|l|}{ Frekuensi Mandi } \\
\hline Tidak Mandi & 18 & 19,0 & 10 & 10,5 & 28 & 29,5 & & 0.519 \\
\hline Mandi & 52 & 54,7 & 15 & 15,8 & 67 & 70,5 & 0,182 & $0.198-1.360$ \\
\hline Total & 70 & 73,7 & 25 & 26,3 & 95 & 100 & & \\
\hline \multicolumn{9}{|l|}{ Frekuensi Ganti Popok } \\
\hline$<4 x /$ hari & 11 & 11,6 & 5 & 5,3 & 16 & 16,8 & & 0.746 \\
\hline$\geq 4 x /$ hari & 59 & 62,1 & 20 & 21,0 & 79 & 83,2 & 0,624 & $0.231-2.409$ \\
\hline Total & 70 & 73,7 & 25 & 26,3 & 95 & 100 & & \\
\hline \multicolumn{9}{|l|}{ Waktu Bebas Popok } \\
\hline$<15$ menit/hari & 23 & 24,2 & 12 & 12,6 & 35 & 36,8 & & 0.530 \\
\hline$\geq 15$ menit/hari & 47 & 49,5 & 13 & 13,7 & 60 & 63,2 & 0,181 & $0.209-1.343$ \\
\hline Total & 70 & 73,7 & 25 & 26,3 & 95 & 100 & & \\
\hline \multicolumn{9}{|l|}{ Penggunaan Antibiotik } \\
\hline$<6$ hari & 35 & 36,8 & 10 & 10,5 & 45 & 47,4 & & 1.500 \\
\hline$\geq 6$ hari & 35 & 36,8 & 15 & 15,8 & 50 & 52,6 & 0,391 & $0.593-3.791$ \\
\hline Total & 70 & 73,7 & 25 & 26,3 & 95 & 100 & & \\
\hline \multicolumn{9}{|l|}{ Penggunaan Krim Popok } \\
\hline Tidak & 70 & 73,7 & 17 & 17,9 & 87 & 91,6 & & 6651953682.084 \\
\hline Ya & 0 & 0 & 8 & 8,4 & 8 & 8,4 & 0,999 & $0.000-$ \\
\hline Total & 70 & 73,7 & 25 & 26,3 & 95 & 100 & & \\
\hline \multicolumn{9}{|l|}{ Alat pembersih Popok } \\
\hline Tisu basah & 0 & 0 & 0 & 0 & 0 & 0 & & \\
\hline Aquabides + kasa/kapas & 70 & 73,7 & 25 & 26,3 & 95 & 100 & - & - \\
\hline Total & 70 & 73,7 & 25 & 26,3 & 95 & 100 & & \\
\hline
\end{tabular}




\begin{tabular}{|c|c|c|c|c|c|c|c|c|}
\hline \multirow{3}{*}{ Variabel } & \multicolumn{4}{|c|}{ Ruam Popok } & \multirow{2}{*}{\multicolumn{2}{|c|}{ Total }} & \multicolumn{2}{|c|}{ Regresi Logistik Sederhana } \\
\hline & \multicolumn{2}{|c|}{ Tidak } & \multicolumn{2}{|c|}{ Ya } & & & \multirow{2}{*}{$p$-value } & \multirow{2}{*}{$\begin{array}{c}\text { OR } \\
95 \% \mathrm{Cl}\end{array}$} \\
\hline & $\mathrm{n}$ & $\%$ & $\mathrm{n}$ & $\%$ & $\mathrm{n}$ & $\%$ & & \\
\hline Tidak & 70 & 73,7 & 25 & 26.3 & 95 & 100 & & \\
\hline Ya & 0 & 0 & 0 & 0 & 0 & 0 & - & - \\
\hline Total & 70 & 73,7 & 25 & 26.3 & 95 & 100 & & \\
\hline \multicolumn{9}{|l|}{ Lama Hari Rawat } \\
\hline$<8$ hari & 37 & 39,0 & 7 & 7.4 & 44 & 46.3 & & 2.883 \\
\hline$\geq 8$ hari & 33 & 34,7 & 18 & 18.9 & 51 & 53.7 & $0,036^{*}$ & $1.070-7.768$ \\
\hline Total & 70 & 73,7 & 25 & 26.3 & 95 & 100 & & \\
\hline \multicolumn{9}{|l|}{$\begin{array}{l}\text { Infeksi Kuman/ } \\
\text { Mikroorganisme }\end{array}$} \\
\hline Tidak & 20 & 21.1 & 2 & 2.1 & 22 & 23.2 & & 4.600 \\
\hline Ya & 50 & 52.6 & 23 & 24.2 & 73 & 76.8 & 0,051 & $0.991-1.353$ \\
\hline Total & 70 & 73.7 & 25 & 26.3 & 95 & 100 & & \\
\hline
\end{tabular}

Ket: * signifikan

Tabel 5. Model Akhir Regresi Logistik Ganda Faktor-Faktor yang Berhubungan dengan Kejadian Ruam Popok pada Bayi Baru Lahir, Mei, 2013

\begin{tabular}{lcccc}
\hline \multicolumn{1}{c}{ Variabel } & $\mathrm{B}$ & $\mathrm{p}$-value & OR & $95 \% \mathrm{Cl}$ \\
\hline Frekuensi mandi & 0.566 & 0,561 & 0,568 & $0,084-3,820$ \\
Waktu bebas popok & 0.616 & 0,508 & 0,540 & $0,087-3,353$ \\
Lama hari rawat & 1.369 & $0,012^{*}$ & 3,930 & $1,346-11,480$ \\
Infeksi kuman/mikroorganisme & 2.031 & $0,015^{*}$ & 7,623 & $1,486-39,099$ \\
Constant & -3.530 & 0,016 & 0,029 & \\
\hline
\end{tabular}

Ket: * = signifikan

\section{DAFTAR PUSTAKA}

Adalat, S., Wall, D., \& Goodyear, H. (2007). Diaper dermatitis-frequency and contributory factors in hospital attending children. Pediatric Dermatology, 24(5): 483-488.

Horii, K. A., \& Prossick, T. A. (2012). Overview of diaper dermatitis in infants and children. Retrieved from http://www. uptodate.com/contents/overview-ofdiaper-dermatitis-in-infants-and-children

Humphrey, S., Bergman, J. N., \& Au, S. (2006). Practical management strategies for diaper dermatitis. Skin Therapy Letter, 11(7): 1-6.

Jackson, A. (2008). Time to review newborn skincare. Journal of Neonatal Nursing, electronic edition 4(5): 166-168.

Kartono, J. (2009). Analisis faktor-faktor risiko yang mempengaruhi terjadinya infeksi nosokomial di ruang rawat anak RSUD DR H Abdul Moeloek Bandar Lampung (tesis). Universitas Indonesia, Jakarta, Indonesia.

Li, C., Zhu, Z., \& Dai, Y. (2012). Diaper dermatitis: a survey of risk factors for children aged 1-24 months in china. The Journal of International Medical Research, 40(5): 1752-1760.

Mantoya, C. (2008). Diaper dermatitis: smart and effective management. The American Journal for Nurse Practitioners, 12(9): 11-20.

Mersch, J. \& Shiel, W. C. Jr. (2012). Diaper rash. Retrieved from http://www. medicinenet.com/diaper_rash/article. $\mathrm{htm}$

Mersch, J., \& Stoppler, M. C. (2009). Yeast infection diaper rash. Retrieved from http://www.emedicinehealth.com/yeast_ 
infection_diaper_rash/article_em.htm

Simatupang, M. M. (2009). Candida albicans.

Medan: Departemen Mikrobiologi

Fakultas Kedokteran Universitas

Sumatra Utara.

Visscher, M. O. (2009). Update on the use

of topical agents in neonates. Newborn

\& Infant Nursing Review, 9(1): 31 - 47. 